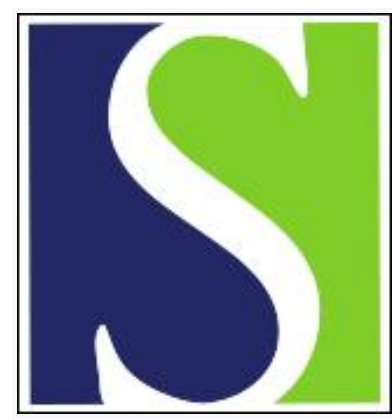

Scand J Work Environ Health 2014;40(1):82-88

https://doi.org/10.5271/sjweh.3379

Published online: 22 Aug 2013, Issue date: 01 Jan 2014

Changes in working conditions and subsequent sickness absence

by Saastamoinen P, Laaksonen M, Lahelma E, Lallukka T, Pietiläinen O, Rahkonen 0

This study examines the association of changes in exposure to several physical working conditions with subsequent sickness absence.

Affiliation: University of Helsinki, Hjelt Institute, Department of Public Health, PO Box 41, 00014 University of Helsinki, Helsinki, Finland. peppiina.saastamoinen@helsinki.fi

Refers to the following texts of the Journal: 2009;35(5):325-333 2007;33(3):233-239

The following articles refer to this text: 2015;41(5):421-424;

2015;41(6):509-510; 2016;42(6):481-489; 2021;47(2):136-144; 2022;48(8):662-671; 2023;49(2):95-98

Key terms: epidemiology; Finland; physical working condition; sick leave; sickness absence; sychosocial working condition; working condition

This article in PubMed: www.ncbi.nlm.nih.gov/pubmed/23970344

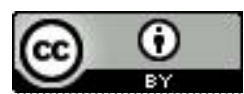




\title{
Changes in working conditions and subsequent sickness absence
}

\author{
By Peppiina Saastamoinen, PhD, ${ }^{1}$ Mikko Laaksonen, PhD, ${ }^{2}$ Eero Lahelma, PhD, ${ }^{1}$ Tea Lallukka, PhD, ${ }^{1,3}$ \\ Olli Pietiläinen, MSocSci, ${ }^{1}$ Ossi Rahkonen, $P h D^{1}$
}

\begin{abstract}
Saastamoinen P, Laaksonen M, Lahelma E, Lallukka T, Pietiläinen 0, Rahkonen 0. Changes in working conditions and subsequent sickness absence. Scand J Work Environ Health. 2014;40(1):82-88 doi:10.5271/sjweh.3379
\end{abstract}

\begin{abstract}
Objectives The aim of the study was to examine the associations of changes in exposure to physical and psychosocial working conditions on subsequent sickness absence among ageing municipal employees of the City of Helsinki, Finland.
\end{abstract}

Methods Changes in exposure to working conditions were assessed between baseline (2000-2002) and followup (2007) surveys. Register-based sickness absence information was linked to the survey data $(\mathrm{N}=3739)$ and followed-up from the return of the questionnaire in 2007 to the end of 2010. The study included six measures of physical and two measures of psychosocial working conditions. Negative binomial regression analysis was used to assess the associations and adjust for covariates.

Results Favorable changes in physical working conditions lowered the risk for sickness absence whereas adverse changes increased the risk. Adverse changes in psychosocial working conditions only slightly increased the risk for sickness absence whereas favorable changes were unassociated with sickness absence.

Conclusions Changes in exposure to physical working conditions in particular are associated with subsequent sickness absence. Preventing an increase in exposure to both psychosocial and physical working conditions and promoting a decrease in exposure to physical working conditions likely helps reduce the risk of sickness absence.

Key terms epidemiology; Finland; physical working condition; psychosocial working condition; sick leave.

Health, individual characteristics, functional capacity, and working conditions are key factors affecting sickness absence (1). Previous research has shown that physical working conditions, such as repetitive monotonous work, lifting, or working mainly standing or squatting (2-4), and psychosocial working conditions, such as low job control, are associated with sickness absence $(2,4-8)$. However, the majority of previous studies have measured working conditions at a single time point. Less is known about how changes over time in the exposure to working conditions affect subsequent sickness absence.

Only a few previous studies have focused on the effects of changes in working conditions on subsequent sickness absence. The effect of adverse changes in exposure to job demands, job control, social support, and physical demands on sickness absence was studied among 530 municipal employees of a small Finnish town during and after economic recession (9). Adverse changes were associated with increased risk of medically certified sickness absence spells. A similar study was conducted among 3817 British civil servants (10), but favorable changes in exposure to psychosocial working conditions were included in addition to adverse changes. Adverse changes in exposure to job demands and job control were associated with sickness absence spells of $\geq 7$ days, but favorable changes were not.

In addition to these two prospective cohort studies, the association of changes in exposure to psychosocial and physical working conditions with preceding changes in sickness absence was studied among 679 Finnish food industry employees (11). Adverse changes in exposure to work postures, team spirit, and reactivity were associated with an increase in sickness absence days.

Previous studies on the effects of changes in exposure to working conditions on sickness absence have focused primarily on psychosocial working conditions and often

\footnotetext{
${ }^{1}$ University of Helsinki, Hjelt Institute, Department of Public Health, Helsinki, Finland.

2 Finnish Centre for Pensions, Helsinki, Finland.

3 Finnish Institute of Occupational Health, Helsinki, Finland.
}

Correspondence to: Peppiina Saastamoinen, University of Helsinki, Hjelt Institute, Department of Public Health, PO Box 41, 00014 University of Helsinki, Helsinki, Finland. [E-mail: peppiina.saastamoinen@helsinki.fi] 
examined adverse changes only. Both definition and the assessment of changes have varied between the studies. In the Finnish municipal sector study, the scores of physical work factors were first standardized and +0.5 standard deviation was used to detect change (9). In the British study, the scores of changes in psychosocial work factors were calculated as a percentage of the total scores and $>10$ points change in either direction was defined as a decrease or increase. The reference category has also varied. "Favorable changes" (9) or "stable situation" (10) has been used. The Finnish study on food industry employees used a different approach as simultaneous changes in working conditions and sickness absence were studied. Such changes were detected by subtracting the time 1 values from time 2 values and using these as continuous variables (11).

More evidence on the associations of changes in exposure to working conditions, especially in exposure to physical working conditions with subsequent sickness absence, is needed to provide a comprehensive picture of how changes in working conditions affect subsequent sickness absence. Both adverse and favorable changes should be included. If favorable changes are followed by lower absence rates, sickness absence might be reduced by promoting favorable changes instead of merely preventing adverse changes.

The aim of this study was to examine the associations of changes in exposure to physical and psychosocial working conditions on subsequent sickness absence among ageing municipal employees.

\section{Methods}

This study is part of the Helsinki Health Study, which examines the health and well-being of the ageing employees of the City of Helsinki. The City of Helsinki is the largest employer in Finland with approximately 40000 employees, $72 \%$ of whom are women. It provides basic services to its inhabitants including social and health services, education, cultural services, public transportation, technical and environmental maintenance, and administrative services. The range of occupations is large and heterogeneous with over 100 occupational titles, covering both blue- and white-collar jobs. Our data show that men are most often in managerial or professional positions $(49 \%)$, whereas routine non-manual occupations are the most common among women ( $42 \%)$. Being a manual worker is more common among men (18\%) than women (10\%).

The data consisted of the Helsinki Health Study baseline (2000-2002) and follow-up (2007) questionnaire surveys and the City of Helsinki personnel register data on subsequent sickness absence. All employees reaching $40,45,50,55$, and 60 years in 2000, 2001, and 2002 received the baseline survey. As the cumulative burden of various risk factors over time is more apparent among older employees, 40-60-year-old employees were selected as the target group. Altogether, 8960 employees responded to the baseline survey (response rate: $67 \%$ ), and 7332 to the follow-up survey (response rate: 83\%). As the baseline data were collected over three consecutive years, the period between baseline and follow-up surveys varies between 5-7 years. The survey data were linked to the City of Helsinki personnel register data on sickness absence for those with written consent for such linkage ( $80 \%, \mathrm{~N}=5885)$. Those who retired due to old age $(\mathrm{N}=1009)$ or disability $(\mathrm{N}=197)$ or who were no longer employed by the City of Helsinki ( $\mathrm{N}=433$ ) were excluded. In addition, we excluded those with missing values in any of the study variables $(\mathrm{N}=497)$ to assure the comparability of different models. The final study population comprised 3739 women and men.

\section{Variables}

Sickness absence. Finnish municipal employees are required to attain a medical certificate for sickness absence of more than three days, while shorter absence spells are self-certified. In order to get the certificate, an employee needs to visit a medical professional who assesses and confirms the need for sickness absence. Information of each absence period is entered in the personnel register of the City of Helsinki. We used medically certified sickness absence spells of longer than three days as the outcome. Consecutive absence spells were combined if there were no workdays between the spells.

Physical working conditions. Physical working conditions were measured with six items (yes or no): (i) awkward postures, (ii) rotation of back, (iii) repetitive movements, (iv) standing, (v) walking, and (vi) heavy physical effort or lifting and carrying heavy loads.

Changes in the exposure to physical working conditions were measured by creating a four-category variable of change for each of the six exposures: (i) stable low exposure (no exposure at either baseline or follow-up), (ii) increased exposure (no exposure at baseline, exposure at follow-up), (iii) decreased exposure (exposure at baseline, no exposure at follow-up), (iv) stable high exposure (exposure at both baseline and follow-up). By "adverse changes", we mean that the exposure increased and, by "favorable changes", we mean that the exposure decreased.

Psychosocial working conditions. Psychosocial working conditions were measured with Karasek's job demands and control model (12). Job demands were measured with five questions: (i) "My job requires working very 
fast"; (ii) "My job requires working very hard"; (iii) "I am not asked to do an excessive amount of work"; (iv) "I have enough time to get the job done"; and (v) "I am free from conflicting demands others make". Job control was measured with nine questions: (i) "My job requires that I learn new things"; (ii) "My job requires me to be creative"; (iii) "My job requires a high level of skill"; (iv) "I get to do a variety of things on my job"; (v) "I have a lot to say about what happens on my job"; (vi) "My job involves a lot of repetitive work"; (vii) "My job allows me to make a lot of decisions on my own"; (viii) "I have opportunity to develop my special skills at work"; (ix) "I have very little say about how to do my job". The respondents were asked to rate their job demands and control on a 5-point scale ranging from "strongly agree" to "strongly disagree". The scales were weighed according to a scale construction system designed by Karasek (13). Both dimensions were dichotomized using the median values as cut-off points.

The change in exposure to psychosocial working conditions was measured by dichotomizing the scales by median at both baseline and follow-up, yielding a four-category variable of change: stable low exposure, increased exposure, decreased exposure, and stable high exposure. High exposure to job control and low exposure to job demands is considered beneficial.

Covariates. Further factors taken into account were body mass index (BMI), current smoking (yes/no), frequency of alcohol consumption (seldom, 1-2 times/month, 1-2 times/week, often) and medically certified sickness absence spells one year prior to the date of responding to the baseline survey.

\section{Statistical analysis}

Person-years by the key independent variables and sickness absence spells were calculated for descriptive purposes. Due to overdispersion in the data, negative binomial regression analysis for count data was used to calculate rate ratios (RR) and their $95 \%$ confidence intervals $(95 \% \mathrm{CI})$ to assess the influence of changes in working conditions with subsequent sickness absence and to adjust for covariates. The group where the participants were at baseline (ie, prior to the change) was used as the reference category. This was done to avoid the situation where the reference category would be a group where the person has not been before the examined change in working conditions. For example, when examining decrease in a physical exposure, one must have had such exposure at baseline. Natural logarithm of the follow-up time was included in the models as an offset variable to take into account the follow-up times of unequal length (14). The follow-up of sickness absence started in Autumn 2007, from the day the employee returned the follow-up ques- tionnaire, and ended in the end of 2010. If the employment contract was terminated before this, the follow-up ended at that point. All periods of sickness absence or absence for other reasons (eg, leave of absence, absence to care for a sick child) were subtracted from the followup time. The mean follow-up time was 2.7 years.

Both adverse and favorable changes in the exposure to working conditions were examined. The analyses were first adjusted for age. Further adjustments included BMI, smoking, alcohol consumption, and medically certified sickness absence one year prior to baseline survey. Analyses were done separately for women and men. SPSS version 18.0.2 (SPSS Institute, Chicago, IL, USA) and SAS version 9.2 (SAS Institute, Cary, NC, USA) were used for the analyses.

\section{Results}

The percentages of exposure to physical and psychosocial working conditions at baseline and follow-up are presented in table 1. Exposure to physical working conditions was slightly lower at follow-up than baseline among both genders whereas exposure to psychosocial working conditions remained or increased among women. Among men, exposure to low control increased, but exposure to high demands decreased. Numbers of respondents, person-years, and number of medically certified sickness absence spells per 100 person years by working conditions are presented in table 2 . Among women, the number of medically certified sickness absence spells per 100 person years was typically highest among those with stable high exposure to physical working conditions and lowest among those with stable low exposure. Those, whose exposure to physical working conditions was increased, had a higher number of sickness absence spells than those whose exposure remained low. Those whose exposure to working conditions was decreased had a smaller number of absence

Table 1. Prevalence (\%) of physical and psychosocial working conditions in baseline and follow-up surveys.

\begin{tabular}{lcccc}
\hline & $\begin{array}{c}\text { Baseline } \\
\text { women } \\
(\mathrm{N}=3084)\end{array}$ & $\begin{array}{c}\text { Follow-up } \\
\text { women }\end{array}$ & $\begin{array}{c}\text { Baseline } \\
\text { men } \\
(\mathrm{N}=655)\end{array}$ & $\begin{array}{c}\text { Follow-up } \\
\text { men }\end{array}$ \\
\cline { 2 - 5 } Awkward postures & 77 & 73 & 59 & 51 \\
Rotations of back & 71 & 68 & 54 & 47 \\
Repetitive movements & 72 & 71 & 59 & 55 \\
Standing & 77 & 74 & 71 & 66 \\
Walking & 82 & 83 & 79 & 78 \\
Heavy physical effort, lifting & 52 & 49 & 36 & 31 \\
carrying heavy loads & & & & \\
High job demands & 54 & 54 & 48 & 44 \\
Low job control & 44 & 49 & 39 & 43 \\
\hline
\end{tabular}


spells than those whose exposure to working conditions remained high. Of the psychosocial working conditions, job control showed similar changes as physical working conditions. However, for job demands, the number of sickness absence spells was highest among those with increased exposure. Results for men showed a similar pattern, but were somewhat less consistent.

The effects of adjustments on the associations of changes in exposure to working conditions with sickness absence are presented in table 3. Among women, when

Table 2. Number of respondents, person-years, and medically certified sickness absence spells per 100 person-years by changes in exposure to physical and psychosocial working conditions.

\begin{tabular}{|c|c|c|c|c|c|c|}
\hline & \multicolumn{3}{|c|}{ Women } & \multicolumn{3}{|c|}{ Men } \\
\hline & $\mathrm{N}$ & $\begin{array}{c}\text { Person- } \\
\text { years }\end{array}$ & $\begin{array}{l}\text { Sickness } \\
\text { absence a } \\
\text { spells / } 100 \\
\text { person- } \\
\text { years }\end{array}$ & N & $\begin{array}{c}\text { Person- } \\
\text { years }\end{array}$ & $\begin{array}{l}\text { - Sickness } \\
\text { absence a } \\
\text { spells / } 100 \\
\text { person- } \\
\text { years }\end{array}$ \\
\hline \multicolumn{7}{|c|}{ Awkward postures } \\
\hline Stable low & 464 & 1286 & 53 & 212 & 572 & 35 \\
\hline Increased & 261 & 692 & 83 & 59 & 166 & 53 \\
\hline Decreased & 367 & 1025 & 59 & 111 & 291 & 42 \\
\hline Stable high & 1992 & 5604 & 103 & 273 & 771 & 72 \\
\hline \multicolumn{7}{|c|}{ Rotation of back } \\
\hline Stable low & 611 & 1697 & 50 & 239 & 644 & 34 \\
\hline Increased & 286 & 809 & 88 & 65 & 186 & 53 \\
\hline Decreased & 381 & 1045 & 63 & 106 & 274 & 43 \\
\hline Stable high & 1806 & 5056 & 107 & 245 & 695 & 76 \\
\hline \multicolumn{7}{|c|}{ Repetitive movements } \\
\hline Stable low & 536 & 1475 & 58 & 188 & 510 & 42 \\
\hline Increased & 317 & 880 & 78 & 79 & 221 & 50 \\
\hline Decreased & 360 & 988 & 76 & 108 & 299 & 50 \\
\hline Stable high & 1871 & 5264 & 101 & 280 & 770 & 63 \\
\hline \multicolumn{7}{|l|}{ Standing } \\
\hline Stable low & 443 & 1254 & 60 & 134 & 362 & 40 \\
\hline Increased & 256 & 713 & 89 & 58 & 156 & 59 \\
\hline Decreased & 350 & 957 & 73 & 87 & 230 & 64 \\
\hline Stable high & 2035 & 5684 & 97 & 376 & 1037 & 55 \\
\hline \multicolumn{7}{|l|}{ Walking } \\
\hline Stable low & 268 & 741 & 57 & 79 & 210 & 43 \\
\hline Increased & 278 & 777 & 88 & 57 & 159 & 40 \\
\hline Decreased & 256 & 697 & 74 & 66 & 183 & 47 \\
\hline Stable high & 2282 & 6392 & 94 & 453 & 1247 & 58 \\
\hline \multicolumn{7}{|c|}{$\begin{array}{l}\text { Heavy physical effort, } \\
\text { lifting, carrying heavy } \\
\text { loads }\end{array}$} \\
\hline Stable low & 1207 & 3344 & 63 & 376 & 1012 & 39 \\
\hline Increased & 265 & 715 & 101 & 41 & 110 & 65 \\
\hline Decreased & 379 & 1052 & 81 & 76 & 214 & 75 \\
\hline $\begin{array}{l}\text { Stable high } \\
\text { Job demands }\end{array}$ & 1233 & 3496 & 114 & 162 & 465 & 74 \\
\hline Stable low & 908 & 2487 & 83 & 260 & 690 & 48 \\
\hline Increase & 510 & 1423 & 100 & 80 & 225 & 62 \\
\hline Decrease & 494 & 1367 & 88 & 108 & 297 & 57 \\
\hline $\begin{array}{l}\text { Stable high } \\
\text { Job control }\end{array}$ & 1172 & 3231 & 88 & 207 & 588 & 55 \\
\hline Stable high & 1230 & 3427 & 76 & 311 & 836 & 40 \\
\hline Decreased & 500 & 1373 & 93 & 92 & 263 & 61 \\
\hline Increased & 348 & 997 & 83 & 64 & 172 & 64 \\
\hline Stable low & 1006 & 2810 & 104 & 188 & 529 & 69 \\
\hline Total & 3084 & 8192 & 88 & 655 & 1746 & 54 \\
\hline
\end{tabular}

a Medically certified. adjusting for age only (model 1), an increase in exposure to physical working conditions was associated with a higher risk of sickness absence. For example, those who reported no exposure to awkward postures at baseline but exposure at follow-up (increased exposure) had a 1.61 (95\% CI 1.32-1.95) times higher risk of sickness absence compared to those with no exposure to awkward postures at either time point (stable low exposure). A decrease in exposure to physical working conditions was associated with a lower risk of sickness absence. Adjusting further for health behaviors (BMI, current smoking, and alcohol consumption) and sickness absence prior to baseline survey (model 2), the associations attenuated to some extent but remained, with the exception of walking. For example, the RR for an increase in exposure to awkward postures was 1.44 (95\% CI 1.18-1.76) and 0.68 (95\% CI 0.59-0.97) for a decrease.

Among men, when adjusting for age only, an increase in exposure to awkward postures, rotation of back, and heavy physical effort or lifting and carrying heavy loads was associated with a higher risk of sickness absence. A decrease in exposure to awkward postures and rotation of the back was associated with a lower risk of sickness absence. Adjusting for all covariates strengthened slightly the associations of an increase in awkward postures and attenuated slightly the association of an increase in heavy physical effort or lifting and carrying heavy loads with subsequent sickness absence. The associations of decrease in the exposure to awkward postures and rotations of the back attenuated but remained after adjusting for all covariates.

When adjusting for age only, an increase in the exposure to job demands and a decrease in the exposure to job control were associated with a higher risk of sickness absence among women. An increase in the exposure to job control was associated with a lower risk of absence. Among men, the only association observed was for a decrease in the exposure to job control. The effects of further adjustments were negligible among both genders, but the increase in the exposure to job control lost statistical significance among women.

\section{Discussion}

This study showed that a decrease in the exposure to physical working conditions was followed by a lowered risk for medically confirmed sickness absence. In contrast, an increase in exposure to physical working conditions was followed by an increased risk. An increase in exposure to psychosocial working conditions was followed by a slightly increased risk for sickness absence, but decrease in the exposure to psychosocial working conditions had no effects. 
Table 3. Rate ratios (RR) and 95\% confidence intervals $(95 \% \mathrm{Cl})$ for changes in physical and psychosocial working conditions. Medically certified over three day sickness absence.

\begin{tabular}{|c|c|c|c|c|c|c|c|c|}
\hline & \multicolumn{4}{|c|}{ Women } & \multicolumn{4}{|c|}{ Men } \\
\hline & \multicolumn{2}{|c|}{ Model 1 ${ }^{\mathrm{a}}$} & \multicolumn{2}{|c|}{ Model $2^{b}$} & \multicolumn{2}{|c|}{ Model $1^{\text {a }}$} & \multicolumn{2}{|c|}{ Model $2^{b}$} \\
\hline & $\mathrm{RR}$ & $95 \% \mathrm{Cl}$ & $\mathrm{RR}$ & $95 \% \mathrm{Cl}$ & $\mathrm{RR}$ & $95 \% \mathrm{Cl}$ & $\mathrm{RR}$ & $95 \% \mathrm{Cl}$ \\
\hline \multicolumn{9}{|c|}{ Awkward postures } \\
\hline Decreased $^{c}$ & 0.55 & $0.48-0.64$ & 0.68 & $0.59-0.97$ & 0.59 & $0.43-0.80$ & 0.67 & $0.49-0.92$ \\
\hline Increased d & 1.61 & $1.32-1.95$ & 1.44 & $1.18-1.76$ & 1.62 & $1.09-2.39$ & 1.74 & $1.16-2.60$ \\
\hline \multicolumn{9}{|c|}{ Rotation of back } \\
\hline Decreased & 0.58 & $0.50-0.66$ & 0.68 & $0.59-0.78$ & 0.57 & $0.42-0.78$ & 0.61 & $0.44-0.84$ \\
\hline Increased & 1.76 & $1.48-2.11$ & 1.51 & $1.26-1.81$ & 1.57 & $1.08-2.28$ & 1.29 & $0.88-1.89$ \\
\hline \multicolumn{9}{|c|}{ Repetitive movements } \\
\hline Decreased & 0.74 & $0.64-0.85$ & 0.82 & $0.71-0.94$ & 0.80 & $0.59-1.07$ & 0.77 & $0.57-1.04$ \\
\hline Increased & 1.38 & $1.16-1.65$ & 1.32 & $1.10-1.58$ & 1.15 & $0.81-1.65$ & 1.10 & $0.76-1.59$ \\
\hline \multicolumn{9}{|l|}{ Standing } \\
\hline Decreased & 0.75 & $0.65-0.86$ & 0.79 & $0.68-0.92$ & 1.21 & $0.89-1.65$ & 1.18 & $0.86-1.62$ \\
\hline Increased & 1.51 & $1.25-1.83$ & 1.24 & $1.02-1.51$ & 1.44 & $0.95-2.18$ & 1.47 & $0.96-2.24$ \\
\hline \multicolumn{9}{|l|}{ Walking } \\
\hline Decreased & 0.79 & $0.67-0.93$ & 0.88 & $0.75-1.04$ & 0.81 & $0.57-1.15$ & 0.84 & $0.59-1.21$ \\
\hline Increased & 1.62 & $1.31-2.01$ & 1.23 & $0.99-1.54$ & 0.90 & $0.56-1.46$ & 0.88 & $0.54-1.44$ \\
\hline \multicolumn{9}{|c|}{$\begin{array}{l}\text { Heavy physical effort, lift- } \\
\text { ing, carrying heavy loads }\end{array}$} \\
\hline Decreased & 0.68 & $0.59-0.78$ & 0.78 & $0.68-0.90$ & 1.02 & $0.73-1.43$ & 0.98 & $0.69-1.39$ \\
\hline Increased & 1.65 & $1.40-1.94$ & 1.49 & $1.26-1.76$ & 1.75 & $1.15-2.67$ & 1.66 & $1.08-2.53$ \\
\hline \multicolumn{9}{|l|}{ Job demands } \\
\hline Decreased & 1.01 & $0.89-1.15$ & 0.94 & $0.82-1.07$ & 1.06 & $0.78-1.44$ & 1.05 & $0.77-1.44$ \\
\hline Increased & 1.17 & $1.03-1.34$ & 1.20 & $1.05-1.37$ & 1.28 & $0.92-1.78$ & 0.97 & $0.69-1.38$ \\
\hline \multicolumn{9}{|l|}{ Job control } \\
\hline Decreased & 1.23 & $1.08-1.40$ & 1.17 & $1.03-1.33$ & 1.54 & $1.13-2.09$ & 1.53 & $1.12-2.10$ \\
\hline Increased & 0.80 & $0.69-0.92$ & 0.88 & $0.75-1.02$ & 1.00 & $0.69-1.45$ & 0.91 & $0.62-1.34$ \\
\hline
\end{tabular}

a Adjusted for age.

b Adjusted for age, body mass index (baseline), current smoking (baseline), alcohol consumption (baseline), and prior sickness absence (one year before baseline).

c Comparison group is stable high exposure group.

d Comparison group is stable low exposure group.

Our results concerning physical working conditions correspond with those of municipal employees of a small Finnish town showing that adverse changes (ie, increase in physical demands of work) were associated with an increased risk of sickness absence (9). In addition, our study included several concrete physical working conditions, examining both favorable and adverse changes thereof. A study among Finnish food industry employees included several measures of physical working conditions, but most of those were environmental risks (11). Our study used two similar measures of physical working conditions and the results agree regarding the association of changes in poor work postures with sickness absence, but disagree with the results regarding repetitive movements. However, in the food industry study, changes in working conditions and sickness absence were examined simultaneously; to be precise, changes in sickness absence preceded the changes in working conditions. That makes it difficult to assess the direction of the association and may also partly explain why only a few associations between changes in working conditions and sickness absence were found.

Our results on the changes of exposure to psychosocial working conditions agree with those of a British study (10), which found that adverse changes in job demands and control were associated with subsequent long-term sickness absence while favorable changes were not. Our results also agree with those of a previous Finnish study (9) where adverse changes in job control, job demands, and social support were associated with an increased risk of sickness absence, when comparing those with adverse changes to those with favorable changes in working conditions.

The associations of changes in exposure to physical working conditions were more pronounced than those of psychosocial working conditions. This is in line with the findings of Danish DREAM studies where the associations of physical and psychosocial work factors, measured at one time point, were studied with sickness absence (15). The difference in the strength of the association between the physical and psychosocial working conditions may be due to the fact that physical working conditions are more directly associated with sickness absence as the assessment of work ability includes taking the requirements of work tasks into account. For example back pain may directly prevent an employee from doing physically strenuous work. The way that psychosocial working conditions affect sickness absence is likely to be 
more complicated. Poor psychosocial working conditions may induce stress, and stress may subsequently lead to ill-health and sickness absence. It has been shown that favorable changes in psychosocial working conditions have alleviated some stress-related health problems, such as fatigue, emotional exhaustion, and psychological distress $(16,17)$. However, these conditions may not cause sickness absence, but rather sickness presence.

The analyses were stratified by gender. Adverse physical working conditions were more often reported by women than men. This could be due to the occupational distribution among the employees of the City of Helsinki. Men's largest class is managers and professionals whereas women's largest class is routine non-manuals (eg, assistant and dental nurses, home aids, school helpers, nannies, and nursery school assistants) with physically strenuous work. The associations of changes in working conditions with sickness absence reached less often statistical significance among men. However, this is likely due to the small number of men in this study.

Previous studies have shown that prior absence predicts future absence and health behaviors are associated with sickness absence $(4,8,18,19)$. These factors explained some of the effects of changes in the exposure to working conditions on sickness absence in our study. As poor health is a factor that may inflict changes in work, and the effects of changes may be different among those with poor health, we tested the interaction effect, but none was found.

\section{Methodological considerations}

The strength of this study was that we were able to measure changes in several physical and psychosocial working conditions among a large occupational cohort including over 100 occupational titles. We also were able to link reliable register-based information on sickness absence both before baseline and after the follow-up survey. This allowed us to control for prior sickness absence in addition to controlling for other key covariates.

In this study, the change in exposure to physical working conditions was measured using dichotomous variables. Measuring the change in psychosocial working conditions was more challenging as these measures were continuous scores. To harmonize the measurement of psychosocial and physical working conditions, job control and job demands were used as dichotomous measures. We are aware of the limitations of this approach. In our analyses, we were unable to take into account the magnitude of the change, and we only assessed whether participants had moved from one category to another (eg, from low to high job control category). Overall, measuring the change in exposure to psychosocial working conditions has proven to be quite complex and different approaches have been taken. The association of changes in psychosocial working conditions warrants further studies with comparable and carefully planned study designs and methods. In addition, studies on physical working conditions with more detailed measures (eg, including time per day spent in physically strenuous work) are likely to be beneficial.

Changes in working conditions were measured between the baseline and follow-up surveys. It is possible that additional changes occurred after that, during the three year register-based follow-up of sickness absence. However, we made sensitivity analyses by shortening the follow-up time to one year, but this had negligible effects on the studied associations. This supports the effects of changes being relatively stable over the follow-up period.

Non-response analyses of the baseline data have shown that those in lower occupational positions, men, younger employees, and those with medically certified sickness absence were less likely to respond to the survey. Consenting for data linkage followed a similar pattern, except that men were more likely to provide consent than women. However, the associations of age, gender, and socioeconomic position with participation did not differ by sickness absence $(20,21)$.

Those who were retired full time due to old age or disability, no longer employed by the City of Helsinki during the follow-up survey, or with missing values in the study variables were excluded from the current study. Overall, compared to those included in the study, the excluded were more often older, men, in worker positions, had higher BMI, used less alcohol, and had slightly less often physically strenuous work and slightly more often low job

control. As those who remained employed were likely to be healthier, they may be less often absent from work due to sickness or they may not face the need to change working conditions due to decreased health. This may make the results more conservative. However, all changes are not due to decreased health: changes may occur in the workplace due to planned or unplanned processes that may be independent from employee health or baseline working conditions. In this case, it is unlikely that these differences would substantially bias the results.

These results describe employees of the City of Helsinki. They are likely apply to the whole municipal sector and might even reflect the associations of changes in working conditions with sickness absence more generally.

\section{Concluding remarks}

We found changes in physical working conditions in particular to be associated with subsequent sickness absence. Thus not only working conditions as such but also their changes over time affect sickness absence. Preventing an increase in exposure to both psychosocial and physical working conditions and promoting a 
decrease in exposure to physical working conditions likely helps diminish sickness absence.

\section{Acknowledgments}

The Academy of Finland (grants \# 1129225, \# 1257362) and the Finnish Work Environment Fund (grant \# 4703247) support the Helsinki Health Study. P Saastamoinen is supported by Signe and Ane Gyllenberg Foundation.

\section{References}

1. Benavides FG. Ill health, social protection, labour relations, and sickness absence. Occup Environ Med 2006;63:228-229. http://dx.doi.org/10.1136/oem.2005.025817

2. Voss M, Floderus B, Diderichsen F. Physical, psychosocial, and organizational factors relative to sickness absence: a study based on Sweden Post. Occup Environ Med 2001;58:178-184. http://dx.doi.org/10.1136/oem.58.3.178

3. Labriola M, Lund T, Burr H. Prospective study of physical and psychosocial risk factors for sickness absence. Occup Med (Lond) 2006;56:469-474. http://dx.doi.org/10.1093/occmed/kq1058

4. Lund T, Labriola M, Bang Christensen K, Bultmann U, Villadsen E. Physical work environment risk factors for long term sickness absence: prospective findings among a cohort of 5357 employees in Denmark. BMJ 2006;332:449-452. http:// dx.doi.org/10.1136/bmj.38731.622975.3A

5. Alavinia SM, van den Berg TI, van Duivenbooden C, Elders LA, Burdorf A. Impact of work-related factors, lifestyle, and work ability on sickness absence among Dutch construction workers. Scand J Work Environ Health 2009;35:325-333. http://dx.doi.org/10.5271/sjweh.1340

6. Andrea H, Beurskens AJ, Metsemakers JF, van Amelsvoort LG, van den Brandt PA, Schayck CP. Health problems and psychosocial work environment as predictors of long term sickness absence in employees who visited the occupational physician and/ or general practitioner in relation to work: a prospective study. Occup Environ Med 2003;60:295-300. http://dx.doi.org/10.1136/oem.60.4.295

7. Duijts SF, Kant I, Swaen GM, van der Brandt PA, Zeegers MP. A meta-analysis of observational studies identifies predictors of sickness absence. J Clin Epidemiol 2007;60:1105-1115. http://dx.doi.org/10.1016/j.jclinepi.2007.04.008

8. Laaksonen M, Pitkäniemi J, Rahkonen O, Lahelma E. Work arrangements, physical working conditions, and psychosocial working conditions as risk factors for sickness absence: Bayesian analysis of prospective data. Ann Epidemiol 2010;20:332-338. http://dx.doi.org/10.1016/j. annepidem.2010.02.004

9. Vahtera J, Kivimäki M, Pentti J, Theorell T. Effect of change in the psychosocial work environment on sickness absence: a seven year follow-up of initially healthy employees. J Epidemiol Community Health 2000;54:484-493. http://dx.doi. org/10.1136/jech.54.7.484

10. Head J, Kivimäki M, Martikainen P, Vahtera J, Ferre JE, Marmot MG. Influence of change in psychosocial work characteristics on sickness absence: the Whitehall II study. J Epidemiol Community Health 2006;60:55-61. http://dx.doi. org/10.1136/jech.2005.038752

11. Siukola AE, Virtanen PJ, Luukkala TH, Nygård C-H. Perceived working conditions and sickness absence - a four-year followup in the food industry. Saf Health Work 2011;2:313-320. http://dx.doi.org/10.5491/SHAW.2011.2.4.313

12. Karasek RA. Job demands, job decision latitude, and mental strain: implications for job redesign. Administrative Science Quartely 1979;24:285-308. http://dx.doi.org/10.2307/2392498

13. Karasek RA. Job Content Questionnaire and User's Guide. Revision 1.1. Lowell, MA: Department of Work Environment, University of Massachusetts, 1985.

14. Bang Christensen K, Andersen PK, Smith-Hansen L, Nielsen ML, Kristensen TS. Analyzing sickness absence with statistical models for survival data. Scand J Work Environ Health 2007;33:233-239. http://dx.doi.org/10.5271/sjweh.1132

15. Burr H, Pedersen J, Hansen JV. Work environment as predictor of long-term sickness absence: linkage of self-reported DWECS data with the DREAM register. Scand J Public Health 2011;39:147152. http://dx.doi.org/10.1177/1403494811401480

16. Janssen N, Nijhuis FJ. Association between positive changes in perceived characteristics and changes in fatigue. J Occup Environ Med 2004;46:866-875. http://dx.doi.org/10.1097/01. jom.0000135608.82039.fa

17. Schaufeli WB, Bakker AB, van Rhenen W. How changes in job demands and resources predict burnout, work engagement, and sickness absenteeism. J Organiz Behav 2009;30:893-917. http://dx.doi.org/10.1002/job.595

18. Koopmans PC, Roelen CA, Groothoff JW. Risk of future sickness absence in frequent and long-term absentees. Occup Med (Lond) 2008;58:268-274. http://dx.doi.org/10.1093/ occmed/kqn040

19. Roelen CA, Koopmans PC, Schreuder JA, Anema JR, van der Beek AJ. The history of registered sickness absence predicts future sickness absence. Occup Med (Lond) 2011;61:96-101. http://dx.doi.org/10.1093/occmed/kqq181

20. Laaksonen M, Aittomäki A, Lallukka T, Rahkonen O, Saastamoinen P, Silventoinen K, Lahelma E. Register-based study among employees showed small nonparticipation bias in health surveys and check-ups. J Clin Epidemiol 2008;61:900906. http://dx.doi.org/10.1016/j.jclinepi.2007.09.010

21. Lahelma E, Aittomäki A, Laaksonen M, Lallukka T, Martikainen P, Piha K, Rahkonen O, Saastamoinen P. Cohort profile: the Helsinki Health Study. Int J Epidemiol. 2013;42:722-730. http://dx.doi.org/10.1093/ije/dys039

Received for publications: 13 March 2013 